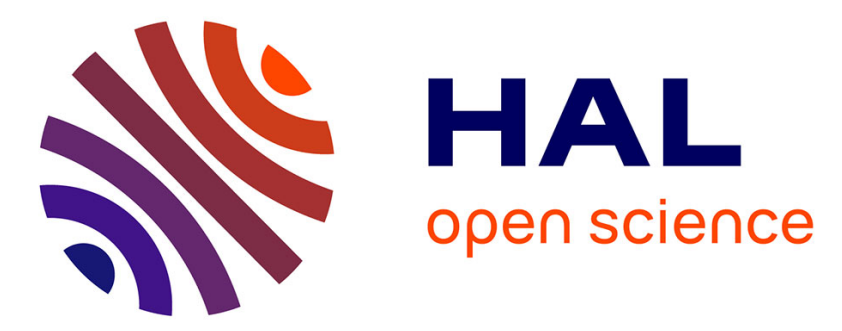

\title{
Dorsal horn NK1-expressing neurons control windup of downstream trigeminal nociceptive neurons
}

Jerome Coste, Daniel L Voisin, Loïs S Miraucourt, Radhouane Dallel, Philippe L Luccarini

\section{- To cite this version:}

Jerome Coste, Daniel L Voisin, Loïs S Miraucourt, Radhouane Dallel, Philippe L Luccarini. Dorsal horn NK1-expressing neurons control windup of downstream trigeminal nociceptive neurons. Pain, 2008, 137 (2), pp.340-351. 10.1016/j.pain.2007.09.017 . hal-01543208

\section{HAL Id: hal-01543208 \\ https://hal.uca.fr/hal-01543208}

Submitted on 21 Jun 2017

HAL is a multi-disciplinary open access archive for the deposit and dissemination of scientific research documents, whether they are published or not. The documents may come from teaching and research institutions in France or abroad, or from public or private research centers.
L'archive ouverte pluridisciplinaire HAL, est destinée au dépôt et à la diffusion de documents scientifiques de niveau recherche, publiés ou non, émanant des établissements d'enseignement et de recherche français ou étrangers, des laboratoires publics ou privés. 


\title{
Dorsal horn NK1-expressing neurons control windup of downstream trigeminal nociceptive neurons
}

\author{
Jérôme Coste ${ }^{1,2,3}$, Daniel L. Voisin ${ }^{1,2}$, Loïs S. Miraucourt ${ }^{1,2}$, \\ Radhouane Dallel $^{1,2,3 *}$, Philippe Luccarini ${ }^{1,2}$
}

1- Inserm E216, Neurobiologie de la douleur trigéminale, Faculté de Chirurgie Dentaire, 11

Boulevard Charles de Gaulle, 63000 Clermont-Ferrand, France

2- Université d'Auvergne, Clermont1, Clermont-Ferrand F-63000, France

3- CHU Clermont-Ferrand, Clermont-Ferrand F-63000, France

* Corresponding author. Address: Inserm E216, Neurobiologie de la douleur trigéminale, Faculte' de Chirurgie Dentaire, 11 Boulevard Charles de Gaulle, 63000 Clermont-Ferrand, France. Tel.: +3347317 73 13; fax: +3347317 7306 .

E-mail address: radhouane.dallel@u-clermont1.fr (R. Dallel).

\begin{abstract}
:
Windup is a progressive, frequency-dependent increase in the excitability of trigeminal and spinal dorsal horn wide dynamic range (WDR) nociceptive neurons to repetitive stimulation of primary afferent nociceptive C-fibers. Superficial dorsal horn neurokinin 1 receptor (NK1R)-expressing neurons were recently shown to regulate sensitization of WDR nociceptive neurons through activation of a defined spino-bulbo-spinal loop. However, the windup of WDR nociceptive neurons was not regulated through this loop. In the present study, we sought to identify the alternative circuit activated by dorsal horn NK1Rs that mediates WDR neuron windup. As a model we used the rat spinal trigeminal nucleus, in which the subnucleus oralis (Sp5O) contains a pool of WDR neurons that receive their nociceptive C-input indirectly via interneurons located in the medullary dorsal horn (MDH). First, we found that intravenous injection of NK1R antagonists (SR140333 and RP67580) produced a reversible inhibition of Sp5O WDR neuron windup. Second, we anatomically identified in the MDH lamina III a subpopulation of NK1R-expressing local interneurons that relay nociceptive information from the $\mathrm{MDH}$ to downstream $\mathrm{Sp5O}$ neurons. Third, using microinjections of NK1R antagonists during in vivo electrophysiological recordings from Sp5O WDR neurons, we showed that WDR neuron windup depends on activation of NK1Rs located in the MDH laminae I-III. We conclude that, in contrast to central sensitization that is controlled by a spinobulbospinal loop, Sp5O WDR neuron windup is regulated through a local circuit activated by MDH lamina III NK1Rs.
\end{abstract}

Keywords: Nociception; Substance P; Trigeminal; Orofacial; Pain 


\section{Introduction}

Pain is clearly a subjective experience that is generated within the brain and integrally associated with emotional, cognitive and learned behaviors. However, nociceptive neurons within the spinal cord dorsal horn $(\mathrm{DH})$ and spinal trigeminal nucleus also analyze and decipher the significance of peripheral inputs before transmitting nociceptive information to higher brain regions [47]. Among these neurons, the wide dynamic range (WDR) nociceptive neurons play a critical role in the sensory discriminative analysis of nociceptive stimuli. In rats, WDR neurons are preferentially located in the deep laminae (IV-VI) of the spinal and medullary DH [57,64] and the subnucleus oralis of the spinal trigeminal nucleus (Sp5O) [15]. Most WDR neurons display a striking form of activity-dependent plasticity referred to as windup. Windup of C-fiber-evoked response consists in a progressive increase in neuronal responses to repetitive thermal or electrical stimulation. Initially described by Mendell [45], this phenomenon occurs in neurons within the dorsal and ventral horns [23] as well as within the spinal trigeminal nuclei $[8,14,21,29]$.

The tachykinin neurokinin1 receptor (NK1R) is the main receptor for substance $\mathrm{P}$, a neurotransmitter that is synthesized by peptidergic afferent $\mathrm{C}$-fibers, local circuit neurons or descending fibers from brainstem [25,32], and released in the superficial spinal DH [26] and the superficial medullary dorsal horn $(\mathrm{MDH})$ [35] upon nociceptive stimulation. In the $\mathrm{DH}$, substance $\mathrm{P}$ acts on two groups of neurons which possess NK1Rs: those with cell bodies in lamina I and also a population of large neurons with cell bodies located in laminae III or IV and dorsal dendrites that enter the superficial laminae [9,53,69]. NK1R-expressing neurons are either interneurons or projecting neurons [69]. Despite the fact that cutaneous peptidergic C-fibers do not reach the deep laminae of the DH or the $\mathrm{Sp} 5 \mathrm{O}$, there is now clear evidence indicating that NK1R activation modulates windup. Indeed, windup is markedly attenuated in rats lacking NK1R-expressing neurons [37,67] as well as in NK1R mutant mice [17,66,71]. Recently, it has been proposed that spinal NK1R-expressing cells in lamina I may act as a critical component in an ascending pathway which results in activation of descending facilitation from the brainstem through serotonergic projections to the spinal DH [67]. Supporting this concept, descending facilitation was blocked by spinal ondansetron, a 5HT3 receptor antagonist [67]. However, windup was not regulated through activation of descending pathways from the brainstem since pharmacologically blocking the pathways had no effect on windup [67]. Thus, the precise neural circuit involved in NK1R-dependent windup is unknown. Here, we used the rat trigeminal system to investigate the question.

\section{Methods}

Adult male Sprague-Dawley rats (280-300 g; Charles River Laboratories, L'Abresle, France) were housed in a temperature-controlled room (22_C; lights on at 07:00 $\mathrm{h}$ and off at 21:00 h). Food and water were available ad libitum. All efforts were made to minimize as much as possible the number of animals used. All procedures adhered to the ethical guidelines of the International Association for the Study of Pain and the European Community Council directive of 24 November 1986 (86/609/EEC).

\section{Trigeminal system}

In the trigeminal system, the MDH is generally considered as the essential brainstem relay of orofacial nociceptive information [18]. However, findings have established the presence of nociceptive neurons in the Sp5O, the majority of which are WDR neurons $[13,14]$. The properties and plasticity of Sp5O WDR neurons clearly match those of WDR neurons in lamina $\mathrm{V}$ of the spinal $\mathrm{DH}$ and $\mathrm{MDH}[14,27,28,58]$. As for neurons of the deep laminae of the 
$\mathrm{DH}, \mathrm{Sp} 5 \mathrm{O}$ neurons are indirectly activated by cutaneous C-fiber input [15,72]. Accordingly, there is evidence for ipsilateral connections between the $\mathrm{MDH}$ and the $\mathrm{Sp5O}$, emanating from laminae III-V of the MDH and to a lesser degree from lamina I and external II [70,72]. Although interneurons located in the superficial laminae are likely to relay nociceptive Cfiber mediated information from the MDH to downstream WDR Sp5O neurons [15,72], interneurons in deep MDH laminae may also be involved since they may receive C-fiber inputs indirectly, via lamina I-II neurons sending axons into deeper layers [39,41,40]. Interestingly, unlike the $\mathrm{DH}$ where the laminae are very close, the $\mathrm{Sp} 5 \mathrm{O}$ is $3 \mathrm{~mm}$ away from the MDH. This allows various pharmacological or electrophysiological manipulations to be made either in the $\mathrm{MDH}$ or in the Sp5O without directly affecting the other structure $[13,15,72]$.

\section{Electrophysiology}

Animal preparation For surgery, the animals $(\mathrm{n}=106)$ were anesthetized with $2 \%$ halothane in a nitrous oxide/oxygen mixture (2/3-1/3). After intraperitoneal injection of $100 \mu \mathrm{g}$ atropine sulphate a tracheal cannula was inserted, the jugular vein was cannulated, the animals were paralysed by an intravenous perfusion of pancuronium bromide $(0.5 \mathrm{mg} / \mathrm{h})$ and artificially ventilated with a volume-controlled pump (54-55 strokes/min). The levels of halothane, $\mathrm{O} 2$, $\mathrm{N} 2 \mathrm{O}$ and the end-tidal CO2 (3.5-4.5\%) were monitored by an anesthetic gas monitor (Artema MM 200, Sundbyberg, Sweden) during the entire experimental period. These parameters were measured by infra-red absorption, digitally displayed and under the control of alarms. A sufficient depth of anesthesia was judged from the absence of gross fluctuations of heart rate. The vascularization of the cutaneous tissues was periodically checked by observing the color of the paw extremities and the rapidity by which they regained normal color after the application of pressure to the paw. The core temperature was maintained at $38 \pm 0.5^{\circ} \mathrm{C}$ with a homeothermic blanket system.

The animals were placed in a stereotaxic frame with the head fixed in a ventroflexed position (incisor bar dropped $5 \mathrm{~mm}$ under the standard position) by means of an adapted metallic bar. A craniotomy was performed on the right side at the level of the occipitoparietalis suture and the dura mater was removed. After surgery, the level of halothane was reduced to $0.6-0.7 \%$ and maintained at this level during the recording period.

Microinjections Drugs were delivered either in the $\mathrm{Sp5O}$ or the $\mathrm{MDH}$ by two-barrel glass micropipettes (3GC120F-15; Clark Electromedical Instruments, Pangbourne, UK) fixed on the micromanipulator and connected to two Hamilton syringes (1 ll) by means of polyethylene tubing (15). The micropipette was broken back maximally to a diameter of 70-100 $\mathrm{lm}$. The micropipettes and tubing were filled with NK1R antagonist or saline with pontamine sky blue, respectively (for location of the injection site). Injections of drugs were performed with a manual injector over a period of 2 min and monitored by observing the movement of an air bubble in the tubing. The slow rate of injection was chosen to minimize the chance of tissue damage. The micropipettes remained in place throughout the experimental session.

For injection into the MDH the caudal medulla was exposed by removing the overlying musculature, atlanto-occipital membrane and dura mater. The micropipette was positioned stereotaxically above the targeted brainstem site $1 \mathrm{~h}$ before the injection. The micropipette tip was lowered $1.5 \mathrm{~mm}$ below the pial surface and slowly elevated $0.5 \mathrm{~mm}$. The medulla was then covered by $2 \%$ Ringer's solution-agar gel. The coordinates used for microinjection sites were $5.3 \mathrm{~mm}$ posterior to the interaural plane (approximately obex) and 1.0-2.8 $\mathrm{mm}$ lateral to the midline [56]. The micropipette was placed at this level because the mandibular and maxillary trigeminal divisions, which are the main afferent inputs to the Sp5O, are heavily represented in the rostral part of the $\mathrm{MDH}[34,68]$. In addition, anatomical investigations have 
demonstrated that this part of the $\mathrm{MDH}$ is at the origin of ascending intranuclear trigeminal pathways to the Sp5O [70].

Recordings Unitary extracellular recordings were made from $\mathrm{Sp5O}$ neurons with glass micropipettes $(8-10 \mathrm{M})$ filled with a mixture of $5 \% \mathrm{NaCl}$ and pontamine sky blue. The brainstem was explored 2.4-3.0 mm lateral to the midline and between the frontal planes P. 1.1 and P. 2.6 [56]. Single unit activities were amplified and displayed on oscilloscopes and were also led into a window discriminator connected to a CED 1401plus interface (Cambridge Electronic Design) and a PC computer (Spike 2.05 software), to allow sampling and analysis of the spontaneous and evoked neuronal activity. WDR neurons were recognized based on their responses to mechanical and percutaneous electrical stimulations of their receptive field [14]. Specifically, neurons that responded in a graded manner with increasing firing rates to the stimulus range from non-noxious to noxious intensity were classified as WDR cells. Innocuous mechanical stimuli to the skin, mucosa and teeth included air puff, brushing with a soft brush, gentle stroking and light pressure with a blunt probe. Noxious mechanical stimuli consisted of heavy pressure, pinprick and pinching with fine forceps (tip area $1 \mathrm{~mm} 2$ ) which evoked a painful sensation when applied to the experimenters' skin. Once a neuron had been identified, its receptive field was mapped and classified according to its location: intraoral, perioral or more peripheral regions of the face [14]. Electrical square-wave stimuli $(2 \mathrm{~ms}$ duration) were applied through a pair of stainless steel stimulating electrodes subcutaneously placed into the center of the previously delineated receptive field and thresholds for eliciting A- and C-fiber responses determined. In post-stimulus time histograms, C-and A-fiber responses were distinguished according to their latencies. It was previously shown that burst discharges at latencies $>30 \mathrm{~ms}$ are elicited by C-fibers [14,29]. Therefore, all spikes between 30- and 300-ms post-stimulus were considered as C-fiber- evoked.

Experimental design The conditioning stimulation to elicit windup consisted of 30 electrical stimuli $(0.66 \mathrm{~Hz}$; three times C-fiber activation threshold) of the excitatory receptive field of the recorded neuron. This stimulation was repeated at 5 or 10 min intervals. During repetitive stimulation, C-fiber-evoked responses of trigeminal WDR neurons progressively increased, thereafter, reached a maximum or peak and then plateaued or slightly decreased. Fits of the windup plots were obtained using a least square fitting algorithm. The dynamic properties of the successive responses were best fitted using a second- order polynomial regression $(\mathrm{R} 2=$ 0.99), indicating that in all cases there was a strong correlation between the amplitude of the response and the number of repetitive stimuli. Since the initial slope of the polynomial fit curves (coefficient of the first degree of $\mathrm{x}$ ) corresponded to the ability of the neuron to amplify its response, it was used to quantify windup.

When two successive control sequences with a variation of $<10 \%$ in the magnitude of C-fiberevoked responses had been recorded, NK1R antagonists (SR140333 and RP67580; gift from Sanofi Research, Montpellier, France) and the respective inactive enantiomers (SR140603 and RP67581) were delivered either intravenously $(\mathrm{n}=53)$ or microinjected into the Sp5O ( $\mathrm{n}$ $=8)$, the MDH laminae I- III $(\mathrm{n}=38)$ or adjacent structures $(\mathrm{n}=7)$. The doses of SR140333 and RP67580 were selected based on published reports [5,12,19,20,30,42,44,46]. Responses were recorded up to $90 \mathrm{~min}$ after drug application. Responses - either windup slope or number of spikes - were normalized to the averaged two responses recorded prior to applying the drug (baseline). If the NK1R antagonist effect did not attenuate the unit response to less than $80 \%$ of the control response, the neuron was considered as insensitive to NK1R activation. In each animal, only one cell was tested, and only cells showing no alteration in spike amplitude or waveform during the complete experimental procedure were considered. 
Histological analysis Recording and microinjection sites were visualized by injection of pontamine sky blue solution at the end of the experiment. After the animal was killed by injection of a lethal dose of pentobarbital, the brain was removed and fixed in a $10 \%$ formalin solution for 1 week. The tissue was frozen, cut into serial $100 \mathrm{~lm}$ thick sections, and stained with neutral red. Recording and microinjection sites were determined by microscopic examination and then plotted on camera lucida drawings of serial sections.

\section{Neuroanatomy}

Animals $(\mathrm{n}=9)$ were anesthetized with chloral hydrate $(7 \%, 400 \mathrm{mg} / \mathrm{kg}$ body weight, i.p. $)$ and placed in a stereotaxic frame. A glass micropipette containing the retrograde fluorescent tracer Fluorogold was inserted stereotaxically so that its tip (30-40 $\mu \mathrm{m}$ diameter) was located within the right Sp5O (AP_1.5 to _2.5 mm, ML $3 \mathrm{~mm}, \mathrm{P} 6.0-7.6 \mathrm{~mm}$ ) according to [56]. Electrophoretic application of Fluorogold was made by $10 \mathrm{~s}$ pulses of positive direct current (3-5 1A) applied every $20 \mathrm{~s}$ for a period of 8-12 min. The microelectrode was left in situ for a further 5 min before withdrawal from the brain. One single application was made in the Sp5O per animal.

One week later, rats were anesthetized deeply with pentobarbital $(50 \mathrm{mg} / \mathrm{kg}$ i.p. $)$ and then were perfused transcardially with warm $\left(37{ }^{\circ} \mathrm{C}\right)$ heparinized saline $(25 \mathrm{IU}$ heparin/ml) followed by cold $\left(10{ }^{\circ} \mathrm{C}\right)$ phosphate-buffered solution $(0.1 \mathrm{M}, \mathrm{pH} 7.6)$ containing $4 \%$ paraformaldehyde and $0.03 \%$ picric acid for $15 \mathrm{~min}$. A few animals received formalin $(5 \%$ in saline, $100 \mu \mathrm{l}$ ) in the right upper lip 6 min before being perfused. Brainstems were then removed and transferred in the same paraformaldehyde-picric acid solution containing $30 \%$ sucrose at $4{ }^{\circ} \mathrm{C}$ and left overnight. Coronal sections were cut on a freezing microtome $(30 \mathrm{~lm}$ thick) and collected in a $0.05 \mathrm{M}$ Tris-buffered saline (TBS). A set of Sp5O sections was mounted on gelatin-coated slides, coverslipped using Vectashield (Vector, Burlingame, CA, USA) and viewed using a fluorescent microscope to check the location of Fluorogold deposit. Only brainstem sections of animals in which the injection site was located in the Sp5O were processed further. A few selected sections were mounted separately and lightly counterstained with neutral red to help delineate the limits of the anatomical structures.

Free-floating brainstem sections were placed in $1 \%$ normal goat serum for $1 \mathrm{~h}$ before incubation at $4{ }^{\circ} \mathrm{C}$ in a rabbit antibody directed against the NK1R (1:5000, Sigma) for $48 \mathrm{~h}$. Sections were then washed in TBS and placed in Cy3 conjugated goat anti-rabbit (1:600, Jackson Immunoresearch, West Grove, PA, USA) for $3 \mathrm{~h}$ at room temperature. Sections were rinsed in TBS and transferred to gelatinized slides before being coverslipped using Vectashield. All immunolabels were diluted in TBS containing $0.25 \%$ bovine serum albumin and $0.3 \%$ Triton $\mathrm{X}-100$. Specificity controls consisted of the omission of the primary antibody and incubation of sections in inappropriate secondary antibodies. In all these control experiments, no specific staining was evident. Sections were analyzed by fluorescent microscopy to characterize Fluorogold and NK1R immunofluorescence and NK1R internalization, using a Zeiss Axioplan 2 Imaging microscope coupled with a Hamamatsu C4742-95 digital camera. For illustrations of NK1R immunoreactivity numerical images were deconvoluted using Metamorph 6.2 software.

Each injection site was analyzed according to delineation of $\mathrm{Sp5O}$ identified using the Paxinos and Watson atlas [56] and our own myeloarchitectural atlas. Retrogradely labeled cell bodies and NK1R-immunopositive neurons were counted according to their location along five different rostrocaudal planes within the MDH (from 0 to $1600 \mu \mathrm{m}$ at $400 \mu \mathrm{m}$ intervals). The delineation of the MDH was based upon the Paxinos and Watson atlas [56] and our own myeloarchitectural atlas. Brainstem sections were categorized according to their approximate rostrocaudal location from the MDH-subnucleus interpolaris junction. In cell bodies that do 
not contain internalized NK1Rs, the immunoreactivity for NK1R is uniformly distributed on the cell surface. In contrast, in the neurons that have internalized the NK1Rs, the cytoplasm contains bright, immunofluorescent endosomes. In the present study, neurons containing 20 or more endosomes were considered to be internalized [26]. Data are expressed as the sum of the total number of labeled cells counted in the structure from all five sections, which were analyzed (mean per rat \pm SEM). For illustrations, representative examples of the distribution of retrogradely labeled cell bodies were grouped on standard drawings of the MDH.

\section{Statistical analysis}

Results are expressed as means \pm SEM. For statistical analysis, one way ANOVA followed by a post hoc Dunnett's test or t-test was used as indicated. The level of significance was set at $P$ $<0.05$.

\section{Results}

\section{General properties of Sp50 WDR neurons}

A total of 106 WDR neurons were recorded within the Sp5O. Most of the neurons were not spontaneously active. All had an ipsilateral receptive field that included the intraoral or perioral region. They were sensitive to both innocuous and noxious mechanical stimuli and responded by increasing their firing rate as the intensity of the stimuli increased into the noxious range. When $2 \mathrm{~ms}$ percutaneous electrical stimuli were applied to the center of the receptive field of the neurons, responses attributable to peripheral activation of A- and Cfibers could be observed (Fig. 1).

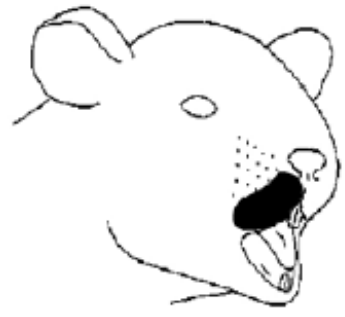

a

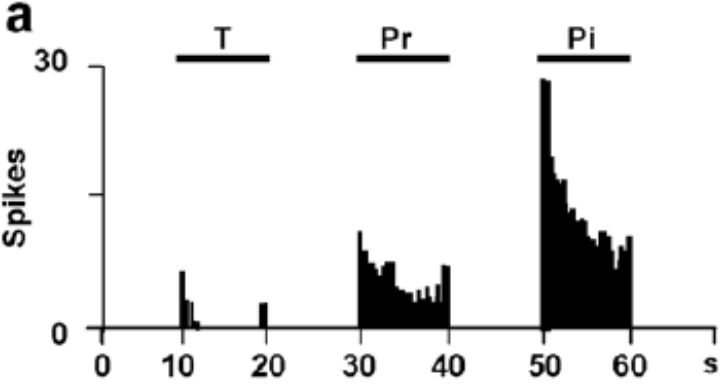

b

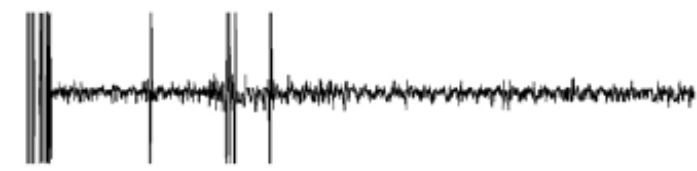

3

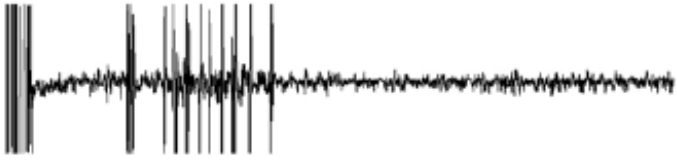

6
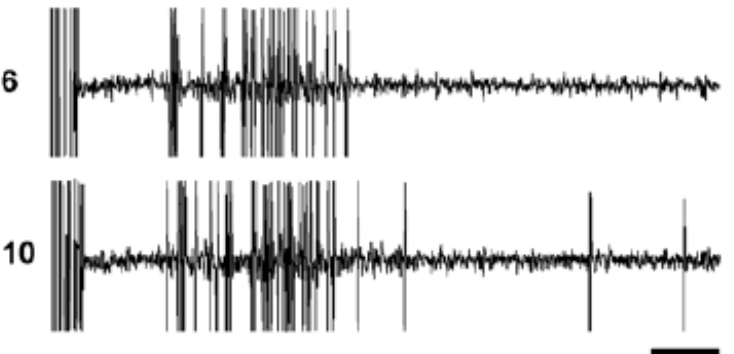

Fig. 1. Example of Sp5O WDR neuron windup. (a) Responses of a neuron to mechanical stimuli (T: touch, Pr: pressure, Pi: pinch) applied to its perinasal receptive field (shown in black). (b) Consecutive single sweep recordings showing the evolution (from top to bottom) of the responses of a single Sp5O WDR neuron following supramaximal (3. threshold, $0.66 \mathrm{~Hz}$ ) percutaneous electrical stimulation applied to its RF. Scale bar: $20 \mathrm{~ms}$.

Responses attributable to C-fibers were obtained at a mean threshold of $8.1 \pm 0.6 \mathrm{~mA}$ and with a mean latency of $84.3 \pm 2.2 \mathrm{~ms}$, which corresponds to a conduction velocity of about 0.6 $\mathrm{m} / \mathrm{s}$. In the present work, the long latency responses that were recorded from Sp5O neurons were due to activation of $\mathrm{C}$-fibers since they could be evoked by high intensity stimulations 
only and exhibited windup during low frequency $(0.66 \mathrm{~Hz})$ suprathreshold electrical stimulation $[23,45]$. Accordingly, it has previously been shown that Sp5O neuron long latency responses could be depressed by intravenous morphine in a naloxone-dependent way [16] and also strongly reduced by intracutaneous injection of capsaicin $(0.1 \%)$, a C-fiber toxin [14]. Windup of C-fiber responses was observed for all recorded Sp5O WDR neurons. This is illustrated by an individual example in Fig. 1 showing a progressive increment of the successive responses to repetitive $(0.66 \mathrm{~Hz})$ percutaneous electrical stimulations applied to the receptive field (Fig. 1). Note that the first stimulation elicited few spikes ( 4-10 spikes) but repetition of the stimulus induced a marked increase of the responses, with a maximum $(\sim 30$ spikes) seen as early as the 10-11th presentation (Figs. 2a and 5a). Beyond, the response plateaued.
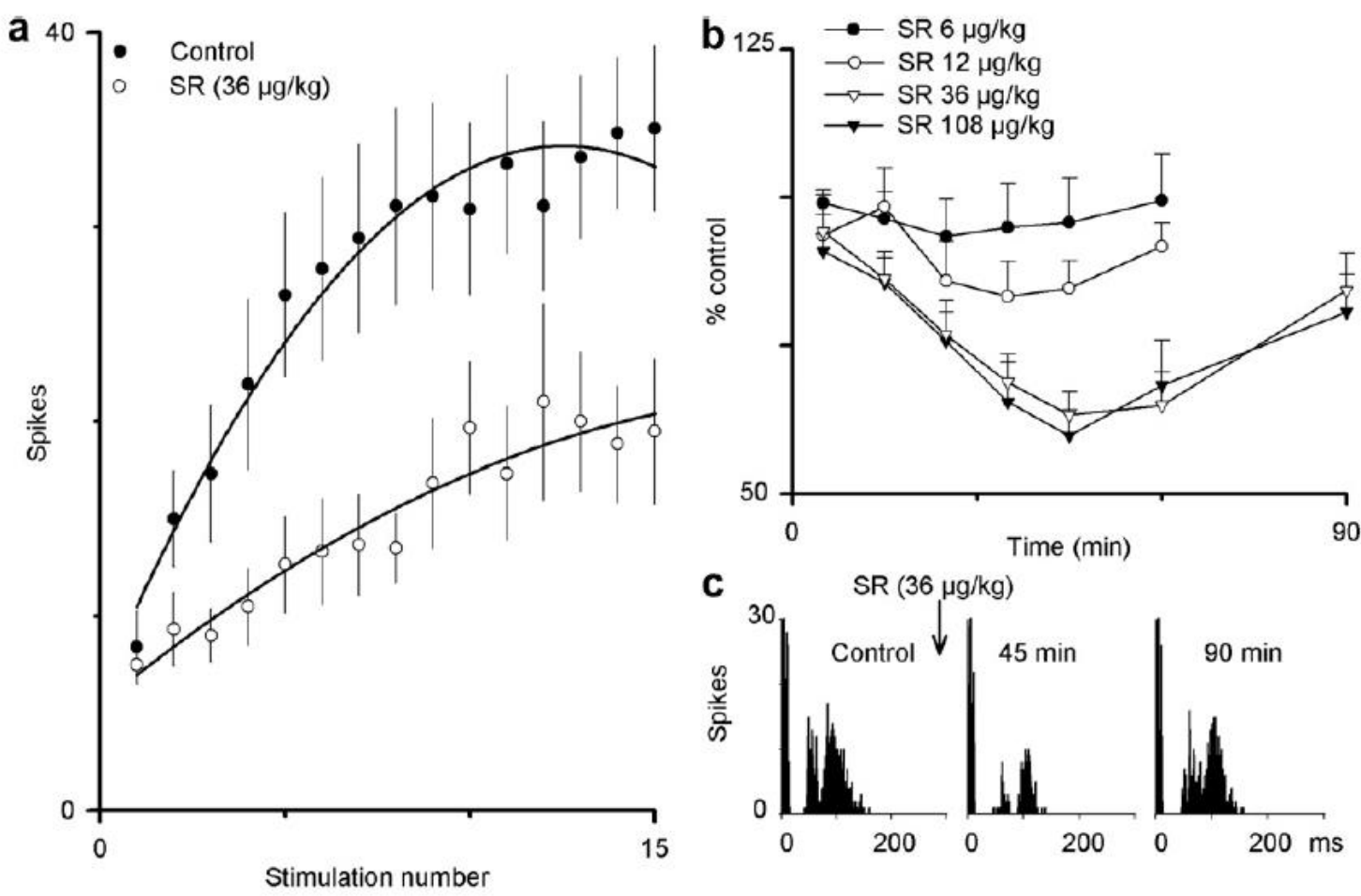

Fig. 2. The windup of Sp50 WDR neuron is NK1R-dependent. (a) Cumulative results illustrating the dynamic properties of the successive responses to 15 stimulations at 3. C-fiber threshold intensity at $0.66 \mathrm{~Hz}$ before (control) and after IV injection of $36 \mathrm{lg} / \mathrm{kg}$ SR140333. Superimposed on the plots are the polynomial fits of the data $\left(n=6\right.$ : before, $y={ }_{-} 0.178 x 2+4.457 x+6.218$; after, $\left.y={ }_{-} 0.038 x 2+1.569 x+5.456\right)$. (b) Cumulative results showing the time course of the effects of IV injection of different doses of SR140333 on the overall Cfiber-evoked responses of Sp5O WDR neurons. (c) Individual example illustrating the effects of IV SRI40333 (36 $\mu \mathrm{g} / \mathrm{kg}$ ) on C-fiber-evoked responses of one single Sp5O WDR neuron.

\section{Windup is NK1R-dependent}

Since recent studies have shown that the windup of DH WDR neurons is attenuated in animals in which NK1R function is impaired [66,67], we investigated whether Sp5O WDR neuron windup is NK1R-dependent. The effects of systemic injection of NK1R antagonists on windup were thus measured $(n=53)$. Since NK1R antagonists may have non-specific effects and limited penetration rate into the brain, two different active molecules, SR140333 and RP67580, as well as the respective inactive enantiomers, SR140603 and RP67581, were tested in parallel. In most neurons (24/29), intravenous injection of SR140333 $(6-108 \mu \mathrm{g} / \mathrm{kg})$ produced a dose-dependent and reversible inhibition of Sp5O WDR neuron windup (Fig. 2a 
and Table 1). SR140603 (108 $\mu \mathrm{g} / \mathrm{kg}, \mathrm{n}=5)$ was inactive. With a dose of $36 \mu \mathrm{g} / \mathrm{kg}$, a maximal reduction of windup by $69 \pm 9 \%(\mathrm{P}<0.004)$ was obtained 45 min after drug injection (Fig. 2b). The effect of SR140333 lasted for 45, 60 and $90 \mathrm{~min}$ with 12,36 and $108 \mu \mathrm{g} / \mathrm{kg}$ of SR140333, respectively. SR140333 also reversibly reduced the overall C-fiber-evoked responses of WDR neurons (Fig. 2b and c and Table 1). A small proportion (5/29) of neurons was not sensitive to SR140333 (108 lg/kg). Consistently, intravenously applied RP67580 (2 $\mathrm{mg} / \mathrm{kg}$ ) also produced a significant and reversible decrease in the windup of 10 out of 14 WDR neurons $(70 \pm 4 \%, \mathrm{P}<0.001$; Table 1$)$. The inhibitory effect of RP67580 was maximal at $40 \mathrm{~min}$ and lasted for $90 \mathrm{~min}$ after injection. RP67581 $(2 \mathrm{mg} / \mathrm{kg}, \mathrm{n}=5)$ had no significant effect.

\begin{tabular}{|c|c|c|c|c|c|c|c|}
\hline \multirow[t]{2}{*}{ Drug, route, dose } & \multirow[t]{2}{*}{ Number of neurons } & \multicolumn{4}{|c|}{ Effect on windup (slope) } & \multicolumn{2}{|c|}{$\begin{array}{l}\text { Effect on overall } \\
\text { C-fiber responses }\end{array}$} \\
\hline & & Before & After & $\%$ decrease & $P$ & $\%$ decrease & $P$ \\
\hline \multicolumn{8}{|l|}{ IV SR140333 } \\
\hline $6 \mu \mathrm{g} / \mathrm{kg}$ & 6 & $3.1 \pm 0.5$ & $2.2 \pm 0.7$ & $40 \pm 18$ & NS & $7 \pm 10$ & NS \\
\hline $12 \mu \mathrm{g} / \mathrm{kg}$ & 6 & $3.9 \pm 0.8$ & $2.1 \pm 0.4$ & $33 \pm 15$ & 0.035 & $22 \pm 5$ & 0.017 \\
\hline $36 \mu \mathrm{g} / \mathrm{kg}$ & 6 & $4.5 \pm 1.0$ & $1.6 \pm 0.5$ & $69 \pm 9$ & 0.004 & $42 \pm 4$ & 0.001 \\
\hline $108 \mu \mathrm{g} / \mathrm{kg}$ & 6 & $7.4 \pm 1.8$ & $3.1 \pm 0.6$ & $42 \pm 18$ & 0.037 & $42 \pm 5$ & 0.009 \\
\hline IV RP67580 (2 mg/kg) & 10 & $4.1 \pm 0.7$ & $1.2 \pm 0.2$ & $70 \pm 4$ & 0.001 & $41 \pm 4$ & 0.001 \\
\hline IC SR140333 $(0.2 \mu \mathrm{g} / 0.5 \mu \mathrm{l})$ & 7 & $4.6 \pm 1.1$ & $2.5 \pm 0.8$ & $47 \pm 15$ & 0.04 & $39 \pm 4$ & 0.003 \\
\hline IC RP67580 $(2 \mu \mathrm{g} / 0.5 \mu \mathrm{l})$ & 10 & $3.7 \pm 0.9$ & $1.4 \pm 0.3$ & $57 \pm 13$ & 0.04 & $43 \pm 9$ & 0.002 \\
\hline
\end{tabular}

Table 1. All values are given as means \pm SEM. Slope values were derived from the initial slope of the polynomial fit curves of the successive responses (see 2) and were rounded off to one decimal digit.

\section{NK1R-expressing interneurons relay nociceptive information from lamina III MDH to downstream Sp5O neurons}

Neurons within the Sp5O are mostly devoid of NK1R [53] and peptidergic C-fiber afferent terminals do not terminate within the $\mathrm{Sp5O}$, except in a portion of the dorsomedial $\mathrm{Sp5O}$ [65]. In contrast, the bulk of trigeminal C-fiber afferent terminals abut caudally, in the superficial laminae of the MDH that contain many NK1R-expressing neurons [9,53]. Since trigeminal neurons have been shown to relay nociceptive C-fiberdependent information from the superficial laminae of the MDH to downstream Sp5O WDR neurons [13,15,72], we hypothesized that NK1R-expressing interneurons may relay substance P-mediated input from the superficial MDH to downstream Sp5O WDR neurons. To chart this pathway, we combined neuroanatomical retrograde tracing from the Sp5O with NK1R immunodetection. Restricted, small injections of the retrograde tracer fluorogold were performed in the right Sp5O of six rats (insets Figs. 3 and 4). Retrogradely labeled cell bodies were mainly found in laminae III-IV and V of the ipsilateral, rostral MDH and to a lesser degree in lamina I and external II (Table 2). The internal lamina II was almost devoid of labeling. Lamina I of the MDH contained many heavily labeled NK1R immunoreactive neurons, while the inner part of lamina II was noticeably devoid of NK1R immunoreactive cells. A distinct band of labeling was located in the dorsal part of lamina III and a few immunoreactive neurons were also found in the deeper lamina V. In four animals, we counted the number of labeled neurons in the population of retrogradely labeled cells. Most double-labeled neurons were found in the dorsal part of lamina III, at rostral levels (18 $\pm 8 \%$ of retrogradely labeled cells in laminae IIIIV; Table 2 and Fig. 3). 
Counts (means \pm SEM) of double-labeled neurons in the population of retrogradely labeled cells and counts (range) of double-labeled neurons in the population of cells exhibiting NK1R endosomes after nociceptive stimulation

\begin{tabular}{lclll}
\hline & \multicolumn{2}{l}{ Non-stimulated } & & Nociceptive-stimulated \\
\cline { 2 - 3 } & $\begin{array}{l}\text { Retrogradely } \\
\text { labeled neurons }\end{array}$ & $\begin{array}{l}\text { Double-labeled } \\
\text { neurons }\end{array}$ & & $\begin{array}{l}\text { Neurons exhibiting NK1 } \\
\text { receptor endosomes }\end{array}$ \\
\hline Laminae I-II & $6 \pm 2$ & $0 \pm 0$ & $18 \pm 0$ & $\begin{array}{l}\text { Double-labeled } \\
\text { neurons }\end{array}$ \\
Laminae III-IV & $61 \pm 26$ & $8 \pm 2$ & $7 \pm 2$ & 0 \\
Lamina V & $33 \pm 20$ & $1 \pm 1$ & $0 \pm 0$ & 0 \\
\hline
\end{tabular}

Table2. Counts were done in five MDH slices of Sp5O Fluorogold injected rats.

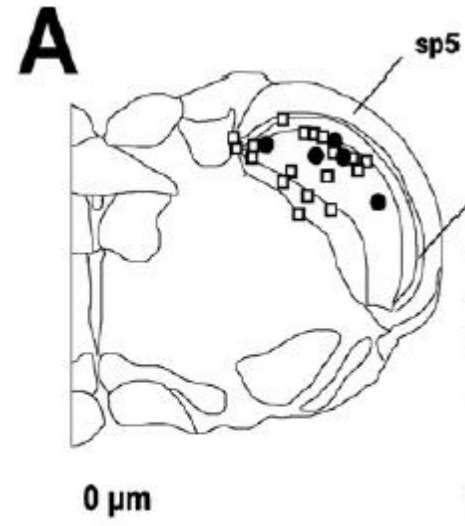

$0 \mu \mathrm{m}$

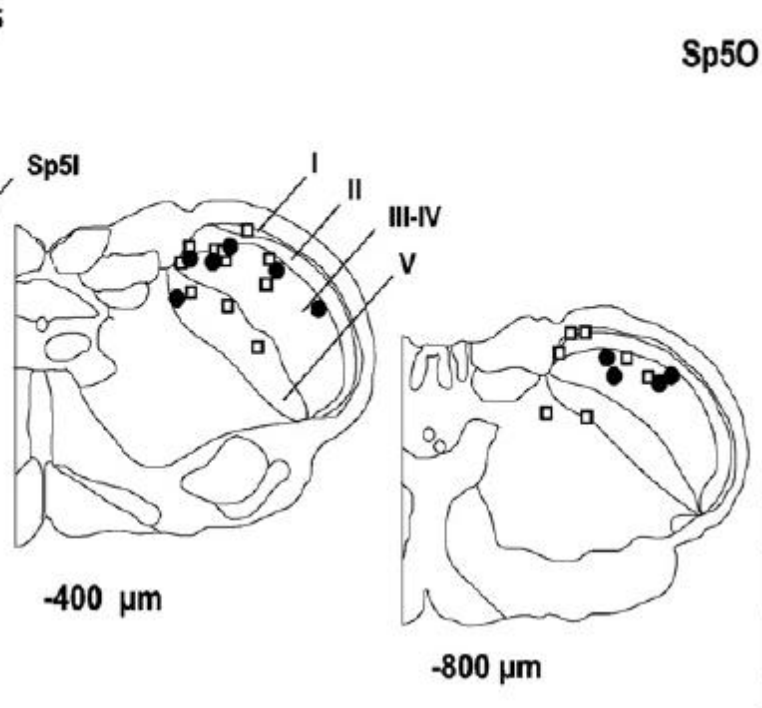

Sp50
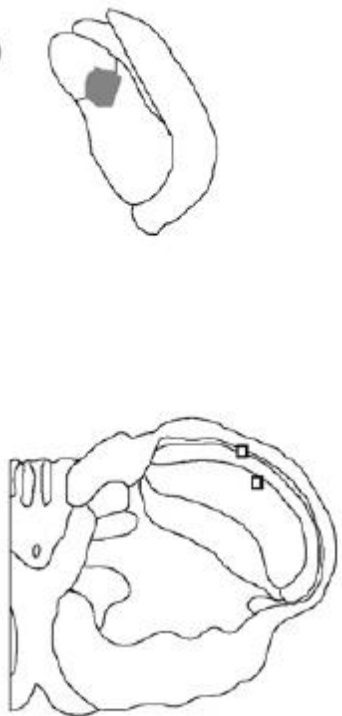

$-1200 \mu \mathrm{m}$
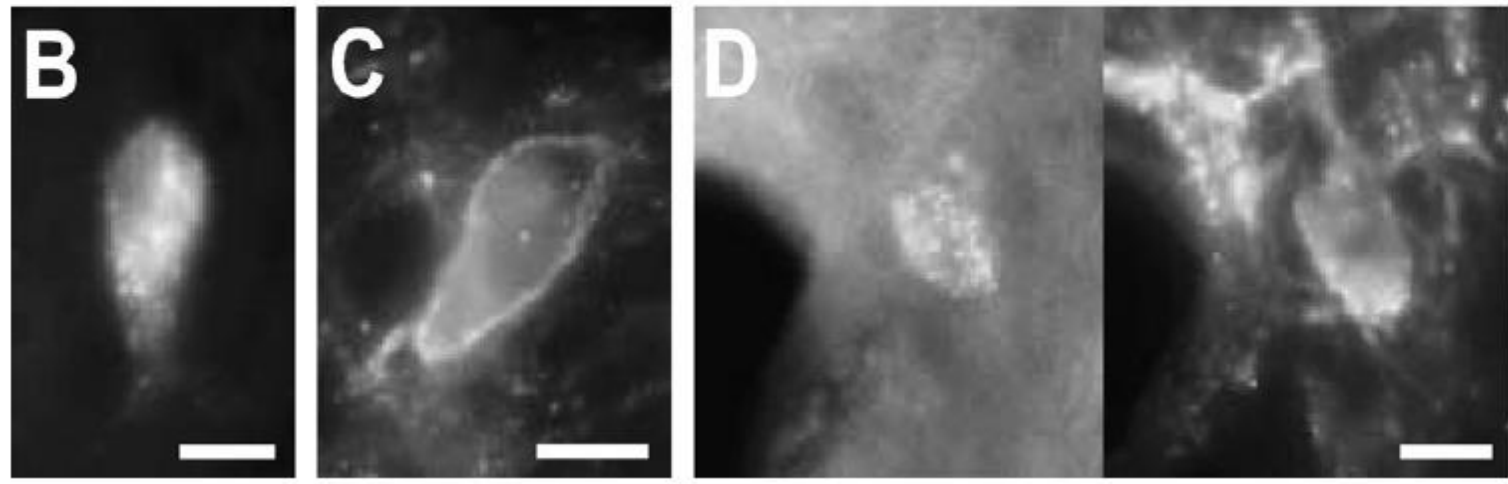

Fig. 3. Neurons connecting the MDH to the Sp5O-expressing NK1Rs. (A) Example of the distribution of the cells of origin of MDH-Sp5O connections expressing NK1Rs (black dots) or not (empty squares) in four selected levels of the MDH of one single animal. Right inset, location of the site of injection in the Sp5O. sp5, spinal trigeminal tract; I-V, MDH laminae; Sp5I, spinal trigeminal sunucleus interpolaris. Numbers show the anteroposterior distance from the coronal plane passing through the Sp5I-MDH junction. (B-D) Numerical images illustrating a retrogradely labeled neuron (B), a NK1-immunopositive neuron (C) and a double-labeled neuron $(D)$ in the MDH. Scale bars: $10 \mu \mathrm{m}$.

In three other animals, $100 \mathrm{ll}$ of 5\% formalin was injected in the right upper lip 6 min before they were perfused with fixative. The noxious stimulus produced strong internalization of the NK1R in ipsilateral lamina I cell bodies, as evidenced by the increase in the proportion of cell bodies exhibiting NK1R endosomes, and in dendrites located in lamina I and II (Fig. 4). It also induced detectable internalization in cell bodies located ventral to the lamina II and lamina III border. In these animals, we counted the number of double-labeled neurons in the 
population of cells exhibiting NK1R endosomes. Nearly all double-labeled neurons were found in the dorsal part of lamina III, at rostral levels (Table 2 and Fig. 4). All together, these results provide anatomical and functional support for C-fiber activation of Sp5O WDR neurons via a subpopulation of NK1Rexpressing neurons located in the superficial part of lamina III.

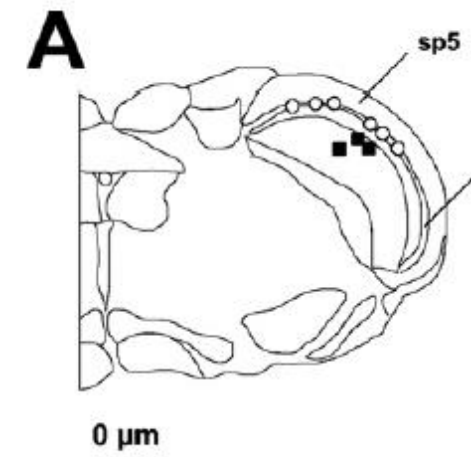

0 um

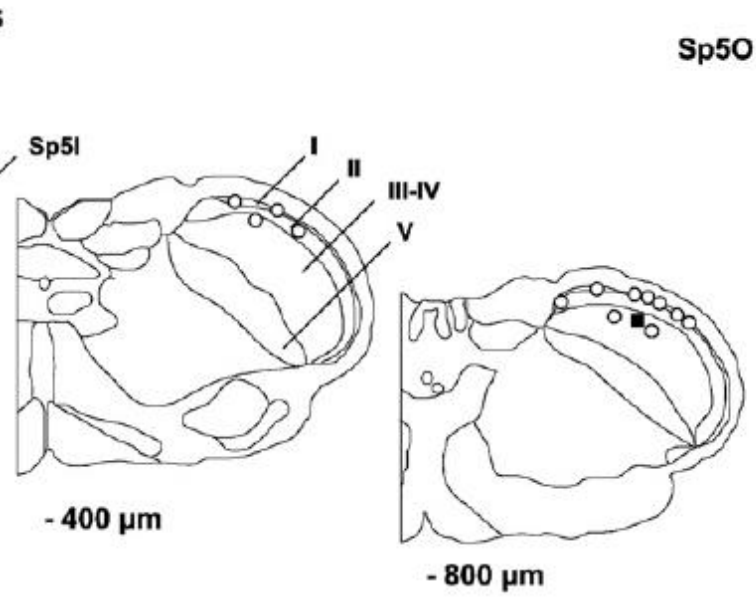

$-800 \mu \mathrm{m}$
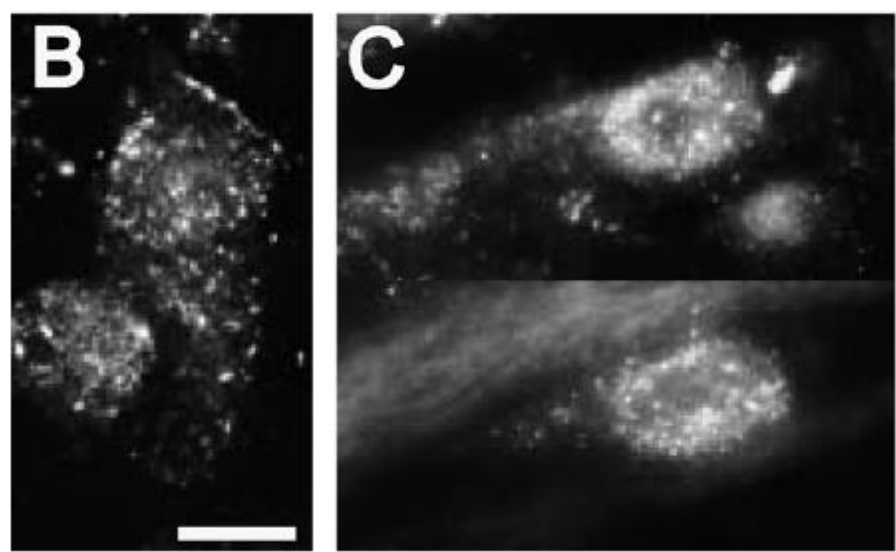

Fig. 4. NK1R internalization in MDH-Sp5O connecting neurons following nociceptive stimulation. (A) Example of the distribution of the cells internalizing NK1Rs in response to upper lip injection of formalin injection in four selected levels of the MDH of one single animal. Neurons also projecting to the Sp5O are indicated by black squares, while the others are given by empty circles. Right inset, location of the site of injection in the Sp5O. sp5, spinal trigeminal tract; I-V, MDH laminae; Sp5I, spinal trigeminal sunucleus interpolaris. Numbers show the anteroposterior distance from the coronal plane passing through the Sp5I-MDH junction. (B) Numerical image illustrating a MDH neuron internalizing NK1Rs. (C) Numerical images illustrating a retrogradely labeled neuron internalizing NK1Rs in the MDH. Scale bars: $10 \mu \mathrm{m}$.

\section{WDR neuron windup depends on activation of MDH NK1Rs}

To assess the role of this population of interneurons in the windup of Sp5O WDR neurons, we tested the effects of microinjections of NK1R antagonists either within the Sp5O or the MDH laminae I-III while recording from Sp5O WDR neurons $(\mathrm{n}=53)$. When microinjected into the Sp5O, SR140333 $(0.2 \mu \mathrm{g}$ in $0.5 \mu \mathrm{L})$ or RP67580 $(2.0 \mu \mathrm{g}$ in $0.5 \mu \mathrm{l})$ never depressed the Cfiber-evoked responses of Sp5O WDR neurons $(n=8$, Fig. 5). 


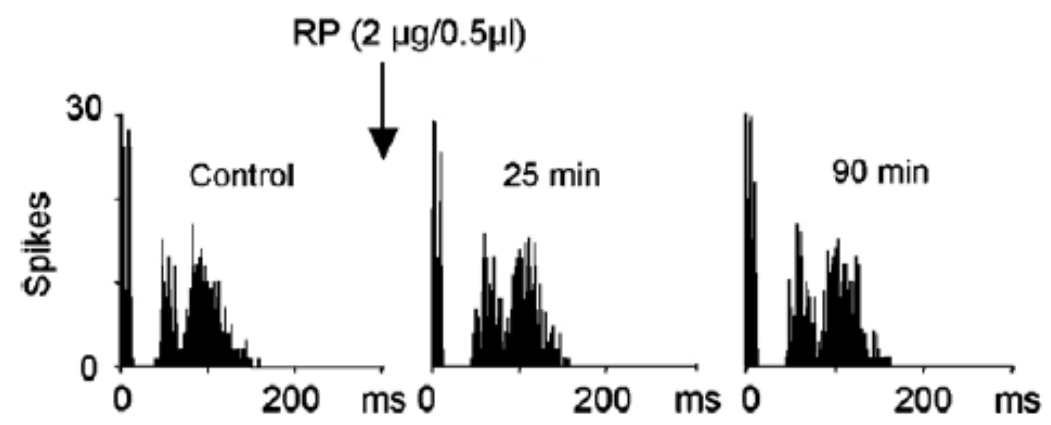

Fig. 5. NKIR antagonists microinjected in the Sp5O do not change Sp5O neuron windup. Individual example illustrating the effects of RP67580 microinjected $(2 \mu \mathrm{g}$ in $0.5 \mu \mathrm{l})$ into the Sp5O on C-fiber-evoked responses of one single Sp5O WDR neuron. The microinjection site is mapped on the right.
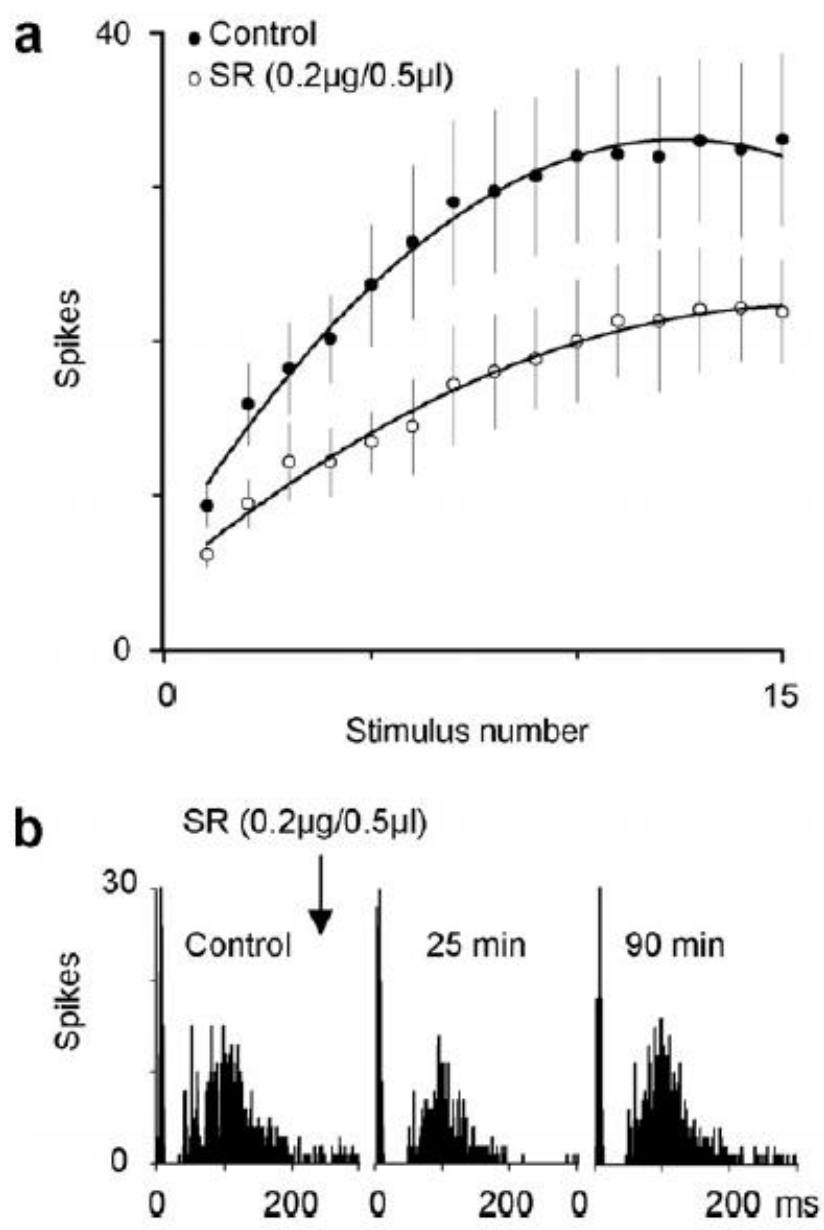

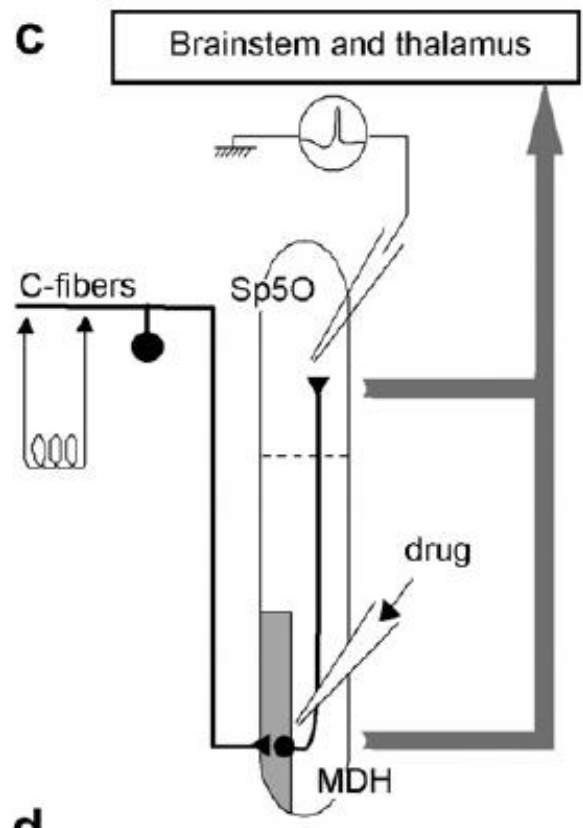

d

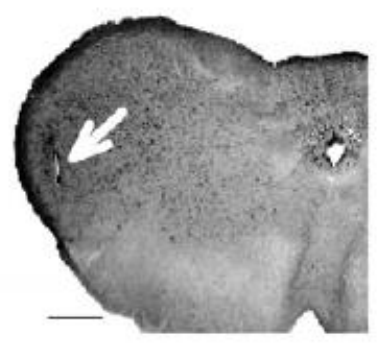

Fig. 6. WDR neuron windup depends on activation of MDH laminae I-III NK1Rs. (a) Cumulative results illustrating the dynamic properties of the successive responses to 15 stimulations at 3. $C$-fiber threshold intensity at $0.66 \mathrm{~Hz}$ before (control) and after microinjection of SRI40333 (0.2 $\mu \mathrm{g}$ in $0.5 \mu \mathrm{l})$ in the MDH laminae I-III. Superimposed on the plots are the polynomial fits of the data $(n=7$ : before, $y=\ldots 0.193 x 2+4.652 x+7.394$; after, $y=\ldots 0.087 x 2+2.515 x+4.861)$. (b) Individual example illustrating the effects of SR140333 microinjected (0.2 lg in $0.5 \mathrm{ll}$ ) in the MDH laminae I-III on C-fiber-evoked responses of one Sp5O WDR neuron. (c) Schematic diagram illustrating the processing of trigeminal C-fiber input to the Sp5O. (d) Example of microinjection site in the MDH laminae I-III. White arrow indicates the center of microinjection. Scale bar: $500 \mu \mathrm{m}$. 
On the contrary, we found that microinjections of SR140333 (0.2 lg in 0.511$)$ within the MDH laminae I-III (Fig. 6d) produced a reversible inhibition of windup in seven out of $15 \mathrm{Sp5O}$ WDR neurons (Fig. 6a). A maximal reduction of windup by $47 \pm 15 \%$ ( $\mathrm{P}<0.04$ ) was obtained $25 \mathrm{~min}$ after injection of the drug and the decreasing effect lasted for a period of 50 min. SR140333 also reduced the overall C-fiberevoked responses of WDR neurons by $39 \pm$ 4\% (P < 0.003, Fig. 6b). Consistently, microinjections of RP67580 (2.0 lg in 0.5 ll) also produced a reversible decrease in the windup of 10 out of 23 WDR neurons. A maximal reduction of windup by $57 \pm 13 \%(\mathrm{P}<0.04)$ was obtained 25 min after injection of the drug and the effect lasted for a period of $60 \mathrm{~min}$. RP67580 reduced the overall C-fiber-evoked responses of WDR neurons by $43 \pm 9 \%$ ( $\mathrm{P}<0.002)$. Histological analysis showed that the effective microinjection sites were all placed in the MDH laminae I-III (Fig. 6d). In contrast, no effect was observed when NK1R antagonists were microinjected outside the MDH laminae I- III $(n=7)$, i.e. within the adjacent medullary reticular nucleus at the level of the obex or within the subnucleus interpolaris.

\section{Discussion}

In this study, the trigeminal brainstem somatosensory system was used to identify the NK1expressing neurons involved in the windup of WDR neurons. We found that Sp5O WDR neuron windup depends on activation of MDH NK1Rs and identified in the MDH lamina III a subpopulation of NK1R-expressing interneurons that relay nociceptive information from DH to downstream WDR neurons.

First, we report that intravenously applied NK1R antagonists caused a significant reduction in the total number of spikes of the C-fiber-evoked response of Sp5O WDR neurons, the long latencies of the effects being likely due to the slow penetration rate of these compounds. These data are in line with previous results demonstrating that windup of WDR neurons depends on the activation of NK1Rs, since NK1R antagonists were found to inhibit windup both in vivo [10] and in vitro [3]. These results are also in agreement with the convincing evidence for an important role of NK1Rs in windup that comes from different studies using NK1 knockout mice [17,66,71]. The NK1R antagonists (SR140333, RP67580) used in the present work have been characterized by their high binding affinity in rat and mouse. However, SR140333 displays a higher affinity for NK1Rs in human than in rat and mouse, whereas RP67580 shows a reverse, though less marked, tendency [19,20,61]. Both compounds have a poor ability to penetrate into the central nervous system under basal conditions [61]. However, rats show an increase in blood-brain barrier permeability following stress such as surgery or anesthesia [6,31,55]. Accordingly, other evidence also suggests centrally mediated effects of systemic injection of the NK1R antagonists RP67580 $[20,38,42,44]$ and SR140333 [19,36,43,46]. Based on such previous results, which indicate brain penetration of systemically injected SR140333 and RP67580, we interpret our data in terms of direct central effects, although peripheral influences cannot be ruled out. The doses of NK1R antagonists used in this work were selected according to the relevant literature in the rat. The RP67580 dose is in the middle range compared to those used in previous behavioral [20] and electrophysiological studies [38,42,44]. In the case of SR140333, we found that intravenous SR140333 dose-dependently, reversibly and stereoselectively inhibited C-fiberevoked responses of Sp5O WDR neurons. The SR140333 dose that reduced significantly nociceptive responses of trigeminal WDR neurons was higher than the one necessary to inhibit responses of thalamic nociceptive neurons in the study by [46], but similar to the one (30 $\mu \mathrm{g} / \mathrm{kg}$, i.v.) used to reduce Fos expression in the MDH in the same work [46]. A similar observation has been reported with morphine [24], in which nociceptive responses of thalamic 
neurons were more sensitive to inhibition than those of trigeminal neurons. Finally, the relatively high doses of SR 140333 that were necessary in our hands could be explained by the intensity of the noxious stimulation we used ( 25 mA), which was about 14 times higher than the one $(0.75 \mathrm{~mA})$ used by [46]. Indeed, the level of antinociception produced by any drug is generally dependent on the intensity of the nociceptive stimulus. Second, our anatomical results indicate that a subpopulation of NK1R-expressing interneurons that are activated by noxious stimulation relay nociceptive information from the MDH lamina III to downstream Sp5O WDR neurons. This conclusion is consistent with previous results demonstrating the existence of ipsilateral connections from the $\mathrm{MDH}$ to the $\mathrm{Sp} 5 \mathrm{O}$ [70] and showing that $\mathrm{Sp5O}$ neurons receive their nociceptive $\mathrm{C}$-input indirectly via the $\mathrm{MDH}[15,72]$. In the spinal $\mathrm{DH}$ as well, deep WDR neurons receive a strong polysynaptic Cfiber input from the superficial laminae $[40,41,51,60]$.

Finally, our internalization study is also in line with previous work showing that in normal animals acute inflammatory pain states and electrical stimulation of C-fibers result in NK1R internalization in cell bodies and dendrites located in the spinal superficial DH only and not ventral to lamina II-lamina III border [26]. In the trigeminal spinal nucleus, however, internalization may be more extensive, reaching laminae III-V [62]. A question is whether the interaction between substance $\mathrm{P}$ and the NK1R occurs only via synaptic neurotransmission or whether extrasynaptic neurotransmission is also involved [62]. Electron microscopic studies examining the relationship between substance P and the NK1R in the spinal DH and MDH suggest that the NK1R is observed at both synaptic and extra-synaptic sites in the plasma membrane of post-synaptic neurons [39]. Thus, substance $\mathrm{P}$ released from primary afferent terminals, from descending pathways or from local MDH interneurons [25,32] might act not only on NK1Rs facing the substance P-containing axon terminals but also at extra-synaptic sites. For instance, when significant amounts of substance $\mathrm{P}$ are released, as following extensive tissue injury, they could diffuse in the extracellular space to act on and internalize NK1Rs located at progressively greater distances from the original site of synaptic release. Here, it might be hypothesized that following repetitive stimulation of C-fibers, substance $\mathrm{P}$ may reach the NK1Rs expressed by the population of interneurons located in the superficial part of the MDH lamina III.

Third, microinjections of NK1R antagonists within the Sp5O never produced any depression of the Cfiber- evoked responses of Sp5O WDR neurons. The lack of inhibitory effect was expected since the Sp5O has been shown to be devoid of NK1Rs [53,59,65]. Accordingly, Henry et al. [22] demonstrated that substance P administered near to the somata of Sp5O neurons does not generally affect their spontaneous firing. On the contrary, we found that microinjections of NK1R antagonists within the MDH laminae I-III reduced partially but significantly windup. Such data are in line with previous results showing that selective ablation of superficial DH NK1R-expressing neurons through the use of a substance $\mathrm{P}$ and saporin conjugate effectively attenuated by $\sim 40 \%$ the windup of deep DH WDR neurons $[37,67]$. We also found that microinjections of NK1R antagonists in structures adjacent but outside the MDH laminae I-III did not change windup. From these results and our anatomical findings, we conclude that a significant part of Sp5O WDR neuron windup depends on activation of lamina III MDH neurons. Indeed, lamina III is known to express a high density of NK1Rs in the trigeminal sensory complex $[9,25]$. One question is why only $50 \%$ of WDR neurons were sensitive to NK1R antagonists when they were applied in the MDH, while $80 \%$ were sensitive when antagonists were systemically injected. Such a difference suggests that only a subset of WDR nociceptive neurons is modulated by substance P released in the MDH. This conclusion is consistent with previous observations showing that only 40-60\% of Fos expression in the spinal DH [11] and the MDH [7,48] is inhibited by NK1R antagonists or depletion of local NK1R expressing neurons [1]. Accordingly, iontophoretically applied 
NK1R agonists affect only $60 \%$ of spinal WDR neurons [54]. NK1R ntagonists also produced a stronger effect, by $\sim 70 \%$, when they were systemically given, compared to the $<50 \%$ effect after MDH microinjections. One possibility is that blockade of activation of NK1R in other brain areas, such as the periaqueductal gray, amygdala and hypothalamus [53], could also be involved and affects $\mathrm{Sp5O}$ neuron responses. Consistent with this idea, intracerebroventricular treatment with SR140333 or other NK1R antagonists depressed the behavioral responses $[4,33,63]$ and reduced the Fos expression in the periaqueductal gray, amygdala, and hypothalamus [4,73] induced by noxious stimulation. All together, these results suggest that, in addition to NK1R recruitment, other mechanisms such as glutamate/NMDA receptors [3,23] as well as intrinsic, nonlinear membrane properties $[49,50]$ contribute to windup.

In summary, Sp5O WDR neuron windup is regulated through a local circuit activated by MDH lamina III NK1Rs. In contrast, NK1 positive spinal projection neurons in the superficial DH project upon higher brain areas and control central excitability through descending pathways from the brainstem. However, NK1R-expressing neurons can also promote central sensitization through segmental processes, by directly modulating the excitability of neighboring neurons [37] and without bulbo-spinal influences, as demonstrated in isolated rat spinal cords $[2,52]$.

\section{Acknowledgements}

We thank AM Gaydier for secretarial assistance and Pr. A. Artola for critical comments of the manuscript. This work was supported by funding from Inserm, MENESR, Direction Générale des Armées (01.34.012.00470.75.01), Fondation Benoit and Université Clermont1 (France).

\section{References}

[1] Abe T, Ohshita N, Sugiyo S, Moritani M, Kobayashi M, Takemura M. Elimination of neurokinin-1 receptor neurons in caudal nucleus reverses the effects of systemic bicuculline on c-Fos expression in rat trigeminal sensory nucleus: I. High intensity electrical stimulation of the trigeminal ganglion. Neuroscience 2005;133:739-47.

[2] Baba H, Doubell TP, Woolf CJ. Peripheral inflammation facilitates A fiber-mediated synaptic input to the substantia gelatinosa of the adult rat spinal cord. $J$ Neurosci 1999;19:859-67.

[3] Baranauskas G, Nistri A. NMDA receptor-independent mechanisms responsible for the rate of rise of cumulative depolarization evoked by trains of dorsal root stimuli on rat spinal motoneurones. Prog Neurobiol 1998;54:349-65.

[4] Baulmann J, Spitznagel H, Herdegen T, Unger T, Culman J. Tachykinin receptor inhibition and c-Fos expression in the rat brain following formalin-induced pain. Neuroscience 2000;95:813-20.

[5] Begon S, Pickering G, Eschalier A, Mazur A, Rayssiguier Y, Dubray C. Role of spinal NMDA receptors, protein kinase $C$ and nitric oxide synthase in the hyperalgesia induced by magnesium deficiency in rats. Br J Pharmacol 2001;134:1227-36.

[6] Ben-Nathan D, Kobiler D, Rzotkiewicz S, Lustig S, Katz Y. CNS penetration by noninvasive viruses following inhalational anesthetics. Ann N Y Acad Sci 2000;917:944-50.

[7] Bereiter DA, Bereiter DF, Tonnessen BH, Maclean DB. Selective blockade of substance P or neurokinin A receptors reduces the expression of c-fos in trigeminal subnucleus caudalis after corneal stimulation in the rat. Neuroscience 1998;83:525-34. 
[8] Bolton S, O'Shaughnessy CT, Goadsby PJ. Properties of neurons in the trigeminal nucleus caudalis responding to noxious dural and facial stimulation. Brain Res 2005;1046:122-9.

[9] Brown JL, Liu H, Maggio JE, Vigna SR, Mantyh PW, Basbaum AI. Morphological characterization of substance $\mathrm{P}$ receptorimmunoreactive neurons in the rat spinal cord and trigeminal nucleus caudalis. J Comp Neurol 1995;356:327-44.

[10] Budai D, Larson AA. Role of substance P in the modulation of Cfiber-evoked responses of spinal dorsal horn neurons. Brain Res 1996;710:197-203.

[11] Chapman V, Buritova J, Honore P, Besson JM. Physiological contributions of neurokinin 1 receptor activation, and interactions with NMDA receptors, to inflammatory-evoked spinal c-Fos expression. J Neurophysiol 1996;76:1817-27.

[12] Chapman V, Dickenson AH. The effect of intrathecal administration of RP67580, a potent neurokinin 1 antagonist on nociceptive transmission in the rat spinal cord. Neurosci Lett 1993;157:149-52.

[13] Chiang CY, Hu B, Hu JW, Dostrovsky JO, Sessle BJ. Central sensitization of nociceptive neurons in trigeminal subnucleus oralis depends on integrity of subnucleus caudalis. J Neurophysiol 2002;88:256-64.

[14] Dallel R, Duale C, Luccarini P, Molat JL. Stimulus-function, wind-up and modulation by diffuse noxious inhibitory controls of responses of convergent neurons of the spinal trigeminal nucleus oralis. Eur J Neurosci 1999;11:31-40.

[15] Dallel R, Duale C, Molat JL. Morphine administered in the substantia gelatinosa of the spinal trigeminal nucleus caudalis inhibits nociceptive activities in the spinal trigeminal nucleus oralis. J Neurosci 1998;18:3529-36.

[16] Dallel R, Luccarini P, Molat JL, Woda A. Effects of systemic morphine on the activity of convergent neurons of spinal trigeminal nucleus oralis in the rat. Eur $\mathrm{J}$ Pharmacol 1996;314:19-25.

[17] De Felipe C, Herrero JF, O'Brien JA, Palmer JA, Doyle CA, Smith AJ, et al. Altered nociception, analgesia and aggression in mice lacking the receptor for substance P. Nature 1998;392:394-7.

[18] Dubner R, Bennett GJ. Spinal and trigeminal mechanisms of nociception. Annu Rev Neurosci 1983;6:381-418.

[19] Emonds-Alt X, Doutremepuich JD, Heaulme M, Neliat G, Santucci V, Steiberg R, et al. In vitro and in vivo biological activities of SR 140333, a novel potent non-peptide tachykinin NK1 receptor antagonist. Eur J Pharmacol 1993;250:403-13.

[20] Garret C, Carruette A, Fardin V, Moussaoui S, Montier F, Peyronel JF, et al. Antinociceptive properties and inhibition of neurogenic inflammation with potent SP antagonists belonging to perhydroisoindolones. Regul Pept 1993;46:24-30.

[21] Hamba M, Hisamitsu H, Muro M. Wind-up of tooth pulp-evoked responses and its suppression in rat trigeminal caudal neurons. Brain Res Bull 1992;29:883-9.

[22] Henry JL, Sessle BJ, Lucier GE, Hu JW. Effects of substance P on nociceptive and nonnociceptive trigeminal brain stem neurons. Pain 1980;8:33-45.

[23] Herrero JF, Laird JM, Lopez-Garcia JA. Wind-up of spinal cord neurones and pain sensation: much ado about something? Prog Neurobiol 2000;61:169-203.

[24] Hill RG, Salt TE, Pepper CM. A comparison of the effectiveness of intravenous morphine at attenuating the nociceptive responses of medullary dorsal horn and thalamic neurones. Life Sci 1982;31:2331-4.

[25] Hokfelt T, Ljungdahl A, Terenius L, Elde R, Nilsson G. Immunohistochemical analysis of peptide pathways possibly related to pain and analgesia: enkephalin and substance P. Proc Natl Acad Sci USA 1977;74:3081-5. 
[26] Honore P, Menning PM, Rogers SD, Nichols ML, Basbaum AI, Besson JM, et al. Spinal substance $\mathrm{P}$ receptor expression and internalization in acute, short-term, and long-term inflammatory pain states. J Neurosci 1999;19:7670-8.

[27] Hu JW, Sessle BJ, Raboisson P, Dallel R, Woda A. Stimulation of craniofacial muscle afferents induces prolonged facilitatory effects in trigeminal nociceptive brain-stem neurones. Pain 1992;48:53-60.

[28] $\mathrm{Hu}$ JW, Woda A, Sessle BJ. Effects of pre-emptive local anaesthesia on tooth pulp deafferentation-induced neuroplastic changes in cat trigeminal brainstem neurones. Arch Oral Biol 1999;44:287-93.

[29] $\mathrm{Hu}$ JW. Response properties of nociceptive and non-nociceptive neurons in the rat's trigeminal subnucleus caudalis (medullary dorsal horn) related to cutaneous and deep craniofacial afferent stimulation and modulation by diffuse noxious inhibitory controls. Pain 1990;41:331-45.

[30] Hua XY, Che P, Marsala M, Yaksh TL. Intrathecal substance Pinduced thermal hyperalgesia and spinal release of prostaglandin E2 and amino acids. Neuroscience 1999;89:525-34.

[31] Huber JD, Witt KA, Hom S, Egleton RD, Mark KS, Davis TP. Inflammatory pain alters blood-brain barrier permeability and tight junctional protein expression. Am J Physiol Heart Circ Physiol 2001;280:1241-8.

[32] Hunt SP, Kelly JS, Emson PC, Kimmel JR, Miller RJ, Wu JY. An immunohistochemical study of neuronal populations containing neuropeptides or gamma-aminobutyrate within the superficial layers of the rat dorsal horn. Neuroscience 1981;10:1883-98.

[33] Improta G, Broccardo M. Effects of supraspinal administration of PG-SPI and PG-KII, two amphibian tachykinin peptides, on nociception in the rat. Peptides 2000;21:1611-6.

[34] Jacquin MF, Semba K, Egger MD, Rhoades RW. Organization of HRP-labeled trigeminal mandibular primary afferent neurons in the rat. J Comp Neurol 1983;215:397-420.

[35] Jessell TM, Iversen LL. Opiate analgesics inhibit substance P release from rat trigeminal nucleus. Nature 1977;268:549-51.

[36] Jung M, Calassi R, Maruani J, Barnouin MC, Souilhac J, Poncelet M, et al. Neuropharmacological characterization of SR 140333, a non peptide antagonist of NK1 receptors. Neuropharmacology 1994;33:167-79.

[37] Khasabov SG, Rogers SD, Ghilardi JR, Peters CM, Mantyh PW, Simone DA. Spinal neurons that possess the substance $\mathrm{P}$ receptor are required for the development of central sensitization. J Neurosci 2002;22:9086-98.

[38] Laird JM, Hargreaves RJ, Hill RG. Effect of RP 67580, a nonpeptide neurokinin1 receptor antagonist, on facilitation of a nociceptive spinal flexion reflex in the rat. $\mathrm{Br} J$ Pharmacol 1993;109:713-8.

[39] Li JL, Wang D, Kaneko T, Shigemoto R, Nomura S, Mizuno N. The relationship between neurokinin-1 receptor and substance $\mathrm{P}$ in the medullary dorsal horn: a light and electron microscopic immunohistochemical study in the rat. Neurosci Res 2000;36:327-34.

[40] Li YQ, Li H, Kaneko T, Mizuno N. Substantia gelatinosa neurons in the medullary dorsal horn: An intracellular labeling study in the rat. J Comp Neurol 1999;411:399-412.

[41] Light AR, Kavookjian AM. Morphology and ultrastructure of physiologically identified substantia gelatinosa (lamina II) neurons with axons that terminate in deeper dorsal horn laminae (III- V). J Comp Neurol 1988;267:172-89.

[42] Liu X, Sandkuhler J. Characterization of long-term potentiation of C-fiber-evoked potentials in spinal dorsal horn of adult rat: essential role of NK1 and NK2 receptors. J Neurophysiol 1997;78:1973-82. 
[43] Luccarini P, Henry M, Alvarez P, Gaydier AM, Dallel R. Contribution of neurokinin 1 receptors in the cutaneous orofacial inflammatory pain. Naunyn Schmiedebergs Arch Pharmacol 2003;368:320-3.

[44] Ma QP, Woolf CJ. Tachykinin NK1 receptor antagonist RP67580 attenuates progressive hypersensitivity of flexor reflex during experimental inflammation in rats. Eur J Pharmacol 1997;322:165-71.

[45] Mendell LM. Physiological properties of unmyelinated fiber projection to the spinal cord. Exp Neurol 1966;16:316-32.

[46] Michaud JC, Alonso R, Gueudet C, Fournier M, Calassi R, Breliere JC, et al. Effects of SR140333, a selective non-peptide NK1 receptor antagonist, on trigemino-thalamic nociceptive pathways in the rat. Fundam Clin Pharmacol 1998;12:88-94.

[47] Millan MJ. Descending control of pain. Prog Neurobiol 2002;6:355-474.

[48] Mitsikostas DD, Sanchez del Rio M. Receptor systems mediating c-fos expression within trigeminal nucleus caudalis in animal models of migraine. Brain Res Rev 2001;35:20-35.

[49] Morisset V, Nagy F. Ionic basis for plateau potentials in deep dorsal horn neurons of the rat spinal cord. J Neurosci 1999;19:7309-16.

[50] Morisset V, Nagy F. Plateau potential-dependent windup of the response to primary afferent stimuli in rat dorsal horn neurons. Eur J Neurosci 2000;12:3087-95.

[51] Nakatsuka T, Furue H, Yoshimura M, Gu JG. Activation of central terminal vanilloid receptor-1 receptors and alpha betamethylene- ATP-sensitive P2X receptors reveals a converged synaptic activity onto the deep dorsal horn neurons of the spinal cord. J Neurosci 2002;22:1228-37.

[52] Nakatsuka T, Park JS, Kumamoto E, Tamaki T, Yoshimura M. Plastic changesin sensory inputs to rat substantia gelatinosaneurons following peripheral inflammation. Pain 1999;82:39-47.

[53] Nakaya Y, Kaneko T, Shigemoto R, Nakanishi S, Mizuno N. Immunohistochemical localization of substance $\mathrm{P}$ receptor in the central nervous system of the adult rat. $\mathrm{J}$ Comp Neurol 1994;347:249-74.

[54] Neugebauer V, Schaible HG, Weiretter F, Freudenberger U. The involvement of substance $\mathrm{P}$ and neurokinin-1 receptors in the responses of rat dorsal horn neurons to noxious but not to innocuous mechanical stimuli applied to the knee joint. Brain Res 1994;666:20715 .

[55] Oztas B, Akgul S, Arslan FB. Influence of surgical pain stress on the blood-brain barrier permeability in rats. Life Sci 2004;74:1973-9.

[56] Paxinos G, Watson C. The rat brain in stereotaxic coordinates. London: Academic Press; 1997.

[57] Price DD, Greenspan JD, Dubner R. Neurons involved in the exteroceptive function of pain. Pain 2003;106:215-9.

[58] Raboisson P, Dallel R, Clavelou P, Sessle BJ, Woda A. Effects of subcutaneous formalin on the activity of trigeminal brain stem nociceptive neurones in the rat. J Neurophysiol 1995;73:496-505.

[59] Rhoades RW, Chiaia NL, Hess PR, Miller MW. Effect of neonatal infraorbital nerve transection on substance $\mathrm{P}$ - and leucine enkephalin-like immunoreactivities in trigeminal subnucleus caudalis of the rat. J Neurosci 1988;8:2234-47.

[60] Ritz LA, Greenspan JD. Morphological features of lamina V neurons receiving nociceptive input in cat sacrocaudal spinal cord. J Comp Neurol 1985;238:440-52.

[61] Rupniak NM, Carlson EJ, Shepheard S, Bentley G, Williams AR, Hill A, et al. Comparison of the functional blockade of rat substance P (NK1) receptors by GR205171, RP67580, SR140333 and NKP-608. Neuropharmacology 2003;45:231-41. 
[62] Sabino MA, Honore P, Rogers SD, Mach DB, Luger NM, Mantyh PW. Tooth extractioninduced internalization of the substance $\mathrm{P}$ receptor in trigeminal nucleus and spinal cord neurons: imaging the neurochemistry of dental pain. Pain 2002;95:175-86.

[63] Santos AR, Calixto JB. Further evidence for the involvement of tachykinin receptor subtypes in formalin and capsaicin models of pain in mice. Neuropeptides 1997;31:381-9.

[64] Sessle BJ. Acute and chronic craniofacial pain: brainstem mechanisms of nociceptive transmission and neuroplasticity, and their clinical correlates. Crit Rev Oral Biol Med 2000;11:57-91.

[65] Sugimoto T, Fujiyoshi Y, Xiao C, He YF, Ichikawa H. Central projection of calcitonin gene-related peptide (CGRP)- and substance $\mathrm{P}$ (SP)-immunoreactive trigeminal primary neurons in the rat. J Comp Neurol 1997;378:425-42.

[66] Suzuki R, Hunt SP, Dickenson AH. The coding of noxious mechanical and thermal stimuli of deep dorsal horn neurones is attenuated in NK1 knockout mice. Neuropharmacology 2003;45:1093-100.

[67] Suzuki R, Morcuende S, Webber M, Hunt SP, Dickenson AH. Superficial NK1expressing neurons control spinal excitability through activation of descending pathways. Nat Neurosci 2002;5:1319-26.

[68] Takemura M, Sugimoto T, Shigenaga Y. Difference in central projection of primary afferents innervating facial and intraoral structures in the rat. Exp Neurol 1991;111:324-31.

[69] Todd AJ. Anatomy of primary afferents and projection neurons in the rat spinal dorsal horn with particular emphasis on substance $\mathrm{P}$ and the neurokinin 1 receptor. Exp Physiol 2002;87:245-9.

[70] Voisin DL, Domejean-Orliaguet S, Chalus M, Dallel R, Woda A. Ascending connections from the caudal part to the oral part of the spinal trigeminal nucleus in the rat. Neuroscience 2002;109:183-93.

[71] Weng HR, Mansikka H, Winchurch R, Raja SN, Dougherty PM. Sensory processing in the deep spinal dorsal horn of neurokinin-1 receptor knockout mice. Anesthesiology 2001;94:1105-12.

[72] Woda A, Blanc O, Voisin DL, Coste J, Molat JL, Luccarini P. Bidirectional modulation of windup by NMDA receptors in the rat spinal trigeminal nucleus. Eur $\mathrm{J}$ Neurosci 2004;19:2009-16.

[73] Yip J, Chahl LA. Distribution of Fos-like immunoreactivity in guinea-pig brain following administration of the neurokinin-1 receptor agonist,[ SAR9,MET(O2)11] substance P. Neuroscience 1999;94:663-73. 